Review began 12/24/2021 Review ended 01/17/2022 Published 01/20/2022

๑) Copyright 2022 Alakeely et al. This is an open access article distributed under the terms of the Creative Commons Attribution License CCBY 4.0., which permits unrestricted use, distribution, and reproduction in any medium, provided the original author and source are credited.

\section{The Ability of Saudi Parents' To Detect Early Language Delay in Their Children: A Study in Primary Health Care Centers, King Abdulaziz Medical City, Riyadh, Saudi Arabia}

\author{
Maha H. Alakeely ${ }^{1,2}$, Howaida Alabbasi ${ }^{1,2}$, Lama Alohali ${ }^{3,2}$, Aida Aldughaither ${ }^{4,1,2}$ \\ 1. Family Medicine, King Abdulaziz Medical City, Ministry of National Guard Health Affairs, Riyadh, SAU 2. Research \\ Center, King Abdullah International Medical Research Centre, Riyadh, SAU 3. Speech Pathology, Child and Adolescent \\ Psychiatry and Behavioral Science, King Abdullah Specialist Children's Hospital, Ministry of National Guard Health \\ Affairs, Riyadh, SAU 4. Family Medicine, College of Medicine, King Saud Bin Abdulaziz University for Health Sciences, \\ Riyadh, SAU
}

Corresponding author: Maha H. Alakeely, mahaakeely@gmail.com

\section{Abstract \\ Purpose}

Our study aims to assess parents' ability to detect early language delay in their children in association with related demographic and environmental factors to help in predicting its risk.

\section{Methods}

A cross-sectional study was conducted at three main primary health care centers at National Guard Health Affairs, Riyadh, Saudi Arabia. Participating parents were asked if they think their children have language delay and if they were able to detect it early. Then, validated age-appropriate screening tools were administered to assess the child's language development. The parents' answers regarding their child's language development were then compared to the screening tool assessment results.

\section{Participants}

A total of 250 parents attending a well-baby clinic for their children's routine vaccinations participated in the study after informed consent was obtained.

\section{Results}

Language delay was more prominent in the one-year-old age group (26.7\%). In addition, children who were not breastfed were significantly more likely to have language delays (P-value 0.014 ). The parents' ability to detect language delay varied among the different age groups. Fifty-seven point one percent (57.1\%) of children aged two years old and $61.5 \%$ of children aged five years old who were found to have language delay were not noticed by their parents (P-value $0.03,0.02$ ).

\section{Conclusion}

Parents showed a lack of ability to detect language delay early. Increasing their awareness of the typical language development milestones and the importance of early intervention is very important to minimize the consequences of late intervention.

Categories: Family/General Practice, Pediatrics

Keywords: parents, early detection, well-baby, delay, language

\section{Introduction}

Language progression and maturation is an essential part of typical development [1]. Language is defined as "the conceptual processing of communication," which includes receptive and expressive language [1-2]. Language development progresses through cooing, bubbling, and then from simple words to phrases and more complex sentences [3]. Although the rate of this progress may vary from one child to another, standardized screening milestones are used to recognize any delays and determine the need for further assessment [4]. Language delay refers to any late development of age-appropriate language skills in the absence of any other justifiable causes like hearing impairment, emotional problems, or cognitive deficits $[5]$.

Several studies from different countries demonstrated the prevalence of language delay among children. In the US, for example, language delay is estimated to be found in $8-9 \%$ of young children [6]. In the UK, six 
studies estimated the prevalence in children aged two to five years old to be between 5\% and 12\% [7]. In India, a study published in 2019 found language delay in about $2.53 \%$ of children aged one to 12 years old [8]. In Iraq, the frequency of language delay was $11.9 \%$ among children aged less than seven years old [9]. Locally, in the Kingdom of Saudi Arabia and among preschool children, the overall prevalence of language delay was dramatically higher, reaching up to $24.5 \%$ [10].

Many factors could contribute to a higher risk of language delay among children. According to a study in Saudi Arabia, groups with a higher risk included males, only children, children with a family history of speech delay, children whose mothers had only high school education, children birthed with a forceps delivery, children with inadequate time spent with their mother and other children, and children that spend more time alone or in front of a screen [10]. In addition, there are some medical risk factors such as having a history of birth asphyxia, seizure disorder, and oropharyngeal deformity [8].

Although a good number of children with an early language delay will catch up as they age, some will have persistent difficulties with their language skills [11]. Early detection and intervention can prevent poor outcomes as a result of language delay and improve the quality of life for the child [12-13]. Some parents are not aware of the typical language milestones. In contrast, some parents recognize the missed milestone but assume that the child will "grow out of it" and catch up with time [11]. This assumption leads to parents seeking medical advice later, which means the precious time of early intervention is lost. Our study aims to assess parents' ability to detect language delays early, measure the percentage of language delays among children attending well-baby clinics, and describe the demographical and environmental factors of parents and their children that could increase the risk for language delay in different age groups.

\section{Materials And Methods \\ Study design, area, and setting}

This cross-sectional study was conducted at the well-baby clinics of three of the Ministry of National Guard Health Affairs (MNGHA) primary health care centers. MNGHA has many primary health care centers distributed around different regions of Saudi Arabia. The Health Care Specialty Centre (HCSC), National Guard Comprehensive Specialized Centre (NGCSC), and King Abdulaziz City Housing (Iskan Yarmouk) center are the main primary health care centers in Riyadh, covering a large population with easy accessibility. Iskan Yarmouk clinics and HCSC serve patients living in the eastern region of Riyadh while NGCSC serves patients living in the northern region. All centers provide general outpatient care with different specialties. Well-baby clinics are responsible for children's vaccines and general well-being. The age of children visiting the clinic is based on the Saudi vaccine schedule starting at two months with regular visits until the age of six. If any problem is noticed during these visits, then the child will be referred for further investigation and management.

\section{Identification of study participants}

The questionnaire was completed by parents attending the well-baby clinic for their children's routine vaccinations. Children who were Saudi nationals, speaking the Arabic language, aged one, one and a half, two, three, and five years were included in the study. Exclusion criteria were applied if the child had oropharyngeal deformities like cleft lip palate or hearing problems or was known to have autism.

\section{Data collection}

A convenience sampling technique was used. Two-hundred fifty parents, either the child's mother or father, who were attending the well-baby clinic for their children's vaccinations were invited to participate in the study. Data were collected by assigned nurses who are working in the well-baby clinics. After the study was explained, parents were asked to sign an informed consent form if they agreed to participate in the study. Data were collected through a self-administered questionnaire distributed to 250 parents. The questionnaire contained three sections. The first included questions related to the child's age, gender, number of siblings, birth order, duration of breastfeeding, and other possible factors associated with language delay. The second section included questions about the parents' age, educational levels, income, and occupation status. The remaining questions in this section focused on whether the parents noticed any language delay in their child and understood the possible risk factors associated with language delay. The last section included screening questions according to the child's age. The Centers for Disease Control and Prevention (CDC)-validated Arabic language milestone screening test was administered to parents based on the child's age. The validity of the questionnaire was assessed by two family physician consultants, two pediatricians, and two speech therapists. After applying their revisions, the completed questionnaire was checked and pretested for clarity and suitability in a small pilot study of ten parents. When administered to the full test group, if the parents answered in the negative to more than $20 \%$ of the screening questions, the subject was categorized as abnormal and in need of further assessment by a speech and language pathologist. The parents' opinion of their child's language development was then compared to the results of the CDC assessment.

\section{Ethical considerations}

Ethical approval was granted by the ethical review board of King Abdullah International Medical Research 


\section{Cureus}

Center, Riyadh, KSA, Reference \#: IRBC/0253/20. Participant consent was obtained through a consent form. The collected data were stored in a secure place where only the principal investigator and co-investigators had access. The data did not contain any identifying information. The names of the participants were coded and stored in a computer with password protection.

\section{Data analysis}

The data were presented as the mean ${ }^{ \pm}$standard deviation for continuous variables (e.g., age of parents) and frequencies (percentages) for categorical variables (e.g., age of children, gender, education level, occupation, etc.) A chi-square test or Fisher's exact test was used to compare categorical variables (e.g., gender, birth order, family income, education level, and language delay). A p-value of < 0.05 was considered statistically significant. Data were entered and analyzed using SPSS software version 23 (IBM Corp., Armonk, NY).

\section{Results}

\section{Parents' demographics}

Table 1 shows the demographic characteristics of parents. The questionnaire was completed by a total of 250 parents, either the child's mother or father. The participated parent filled also his/her partner's related demographic questions. Two-hundred seventeen (86.6\%) of the parents who completed the questionnaire were the mothers. The mean age of the mothers was $31 \pm 4.41$ years. Two-hundred one $(80.4 \%)$ of the mothers were housewives and 122 (48.8\%) had completed college-level education and above. The mean age of the fathers was $36 \pm 7.23$ years. One-hundred seventy-two fathers $(68.8 \%)$ had completed high school education, 241 (96.4\%) were employed, and 140 (56.0\%) had a monthly family income between 5,000 and 10,000 SR.

\begin{tabular}{|c|c|c|}
\hline \multicolumn{2}{|l|}{ Characteristics } & $\mathbf{N}(\%)$ \\
\hline \multirow{2}{*}{ Relation to the child } & Mother & $217(86.8)$ \\
\hline & Father & $33(13.2)$ \\
\hline \multirow{3}{*}{ Age of the mother, $y$} & Below 25 & $22(8.8)$ \\
\hline & Between 25-35 & $169(67.6)$ \\
\hline & More than 35 & $59(23.6)$ \\
\hline \multirow{3}{*}{ Age of the father, $y$} & Below 25 & $3(1.2)$ \\
\hline & Between 25-35 & $130(52.0)$ \\
\hline & More than 35 & $59(46.8)$ \\
\hline \multirow{3}{*}{ Educational level of the mothers } & Illiterate (no education) & $6(2.4)$ \\
\hline & School education ( elementary, intermediate, or high school) & $122(48.8)$ \\
\hline & University degree or above & $122(48.8)$ \\
\hline \multirow{2}{*}{ Education level of the fathers } & School education ( elementary, intermediate, or high school) & $172(68.8)$ \\
\hline & University degree or above & $78(31.2)$ \\
\hline \multirow{2}{*}{ Occupation of the mother } & Employed & $49(19.6)$ \\
\hline & Housewife & $201(80.4)$ \\
\hline \multirow{2}{*}{ Occupation of the father } & Employed & $241(96.4)$ \\
\hline & Unemployed & $9(3.6)$ \\
\hline \multirow{3}{*}{ Family monthly income, Saudi Riyal } & Less than 5000 & $38(15.2)$ \\
\hline & 5000-10000 & $140(56)$ \\
\hline & More than 10000 & $72(28.8)$ \\
\hline
\end{tabular}

TABLE 1: Demographic characteristics of the parents $(n=250)$

\section{Children's demographics}




\section{Cureus}

Table 2 shows the demographic characteristics of the children. A total of 250 children aged one, one and a half, two, three, and five were included in the study. One-hundred twenty-four (56.8\%) were males. Onehundred sixty-seven (66.80\%) were breastfed, with 160 (64\%) breastfed for a duration of less than six months. Two-hundred forty-seven (98.80\%) lived with both parents, and 192 (76.80\%) lived with extended family. A nanny or someone other than the parents took care of 49 (19.6\%) participants. One-hundred eighty-eight (75.20\%) had siblings, with 84 (33.6\%) being the first child. Two-hundred thirty-four (93.60\%) of the children were not attending nursery or school. Eighty-two (33.06\%) of the parents reported screen time of their children of less than one hour per day, mostly with smartphones (56.7\%). 


\section{Cureus}

\begin{tabular}{|c|c|c|}
\hline \multicolumn{2}{|l|}{ Characteristics } & \multirow{2}{*}{\begin{tabular}{|l}
$\mathbf{N}(\%)$ \\
$71(28.4)$ \\
\end{tabular}} \\
\hline \multirow{5}{*}{ Age, y } & 1 & \\
\hline & 1.5 & $40(16.0)$ \\
\hline & 2 & $63(25.2)$ \\
\hline & 3 & $32(12.8)$ \\
\hline & 5 & $44(17.6)$ \\
\hline \multirow{2}{*}{ Gender } & Female & $108(43.2)$ \\
\hline & Male & $142(56.8)$ \\
\hline \multirow{2}{*}{ Living with both parents } & Yes & $247(98.8)$ \\
\hline & No & $3(1.2)$ \\
\hline \multirow{2}{*}{ Living with extended family } & Yes & $58(23.2)$ \\
\hline & No & $192(76.8)$ \\
\hline \multirow{3}{*}{ Nanny or someone else is taking car } & Yes & $49(19.6)$ \\
\hline & No & $201(80.4)$ \\
\hline & Yes & $188(75.2)$ \\
\hline Siblings & No & $62(24.8)$ \\
\hline \multirow{4}{*}{ Birth order } & First child & $84(33.7)$ \\
\hline & Second child & $48(53.0)$ \\
\hline & Third child & $50(20.1)$ \\
\hline & Fourth or more & $67(26.8)$ \\
\hline \multirow{2}{*}{ Attending nursery } & Yes & $16(6.4)$ \\
\hline & No & 234 (93.6) \\
\hline \multirow{2}{*}{ Breastfeeding } & Yes & $167(66.8)$ \\
\hline & No & $83(33.2)$ \\
\hline \multirow{3}{*}{ Breastfeeding duration } & Less than 6 months & $160(64.0)$ \\
\hline & 6 to less than 12 months & $40(16.0)$ \\
\hline & 12 to 24 months & $50(20.0)$ \\
\hline \multirow{4}{*}{ Screen time } & No screen time & $47(19.0)$ \\
\hline & Not more than 1 hour & $82(33.1)$ \\
\hline & Within 2 hours & $52(21.0)$ \\
\hline & More than 2 hours & $67(27.0)$ \\
\hline \multirow{4}{*}{ Devices the child spend time using } & Tablets & $90(36.0)$ \\
\hline & Smartphone & $144(57.6)$ \\
\hline & TV & $97(38.8)$ \\
\hline & Computer & $10(4.0)$ \\
\hline
\end{tabular}

TABLE 2: Demographic characteristics of the children $(n=250)$

The percentage of language delay among participating children 


\section{Cureus}

Among participants who were screened, language delay was detected in $26.7 \%$ of children aged one-yearold, $26.3 \%$ of children aged one and a half years old, $22.2 \%$ of children aged two years old, $22.6 \%$ of children aged three years old, and $31.0 \%$ of children aged five years old (Table 3).

\begin{tabular}{|c|c|c|}
\hline Age of the child, $y(N)$ & Normal language development $\mathrm{N}(\%)$ & Language delay $\mathbf{N}(\%)$ \\
\hline $1(75)$ & $55(73.3)$ & $20(26.7)$ \\
\hline $1.5(38)$ & $28(73.7)$ & $10(26.3)$ \\
\hline $2(63)$ & $49(77.8)$ & $14(22.2)$ \\
\hline $3(31)$ & $24(77.4)$ & $7(22.6)$ \\
\hline $5(42)$ & $29(69.0)$ & $13(31.0)$ \\
\hline
\end{tabular}

TABLE 3: Language delay among participants $(n=250)$

\section{Parent's ability to detect language delay}

To assess the parent's ability to detect their children's language delay, the answers to the question "Do you think your child has a language delay?" were compared to the screening tool results. The results were varied among the different age groups (Table 4). Significantly, children aged two and five years old, who were determined to have a language delay by the assessment tool were not picked up by their parents ( $\mathrm{P}$-value $0.03,0.02)$.

\begin{tabular}{|c|c|c|c|c|}
\hline \multirow{2}{*}{ Age, y } & \multirow{2}{*}{ Language assessment } & \multicolumn{2}{|c|}{ Do you think your child has a language delay? } & \multirow{2}{*}{ P-value } \\
\hline & & Yes & No & \\
\hline \multirow{2}{*}{1} & No language delay & $7(12.7 \%)$ & $48(87.3 \%)$ & \multirow{2}{*}{0.55} \\
\hline & Language delay & $2(10.0 \%)$ & $18(90.0 \%)$ & \\
\hline \multirow{2}{*}{1.5} & No language delay & $1(3.6 \%)$ & $27(96.4 \%)$ & \multirow{2}{*}{0.16} \\
\hline & Language delay & $2(20 \%)$ & $8(80.0 \%)$ & \\
\hline \multirow{2}{*}{2} & No language delay & $3(6.1 \%)$ & $46(93.9 \%)$ & \multirow{2}{*}{0.003} \\
\hline & Language delay & $6(42.9 \%)$ & $8(57.1 \%)$ & \\
\hline \multirow{2}{*}{3} & No language delay & $0(0.00 \%)$ & $24(100 \%)$ & \multirow{2}{*}{0.008} \\
\hline & Language delay & $3(42.9 \%)$ & $4(57.1)$ & \\
\hline \multirow{2}{*}{5} & No language delay & $0(0.00 \%)$ & $29(100 \%)$ & \multirow{2}{*}{0.002} \\
\hline & Language delay & $5(38.5 \%)$ & $8(61.5 \%)$ & \\
\hline
\end{tabular}

TABLE 4: Parent's ability to detect language delay

\section{Demographical and environmental factors of children that could predict higher risk for language delay in the one to five-year age groups}

Table 5 presents the associations between the demographic characteristics of the participants and language delay. Among the variables we assessed, more language delay was noticed among children who were not breastfed (P-value 0.014). There was no significant difference in the presence of language delay and birth order, screen time, a specific gender, children not living with extended family, not attending nursery, and no siblings (P-value $=0.06,0.500,0.202,0.871,0.212,0.768,0.188$, respectively). 


\section{Cureus}

\begin{tabular}{|c|c|c|c|c|}
\hline \multicolumn{2}{|c|}{ Demographic characteristics } & No language delay $\mathrm{N}(\%)$ & Language delay $\mathbf{N}(\%)$ & P-value \\
\hline \multirow{2}{*}{ Gender } & Female & 77 (71.3) & $31(28.7)$ & \multirow{2}{*}{0.202} \\
\hline & Male & $109(76.8)$ & $33(23.2)$ & \\
\hline \multirow{5}{*}{ Age, y } & 1 & $53(74.6)$ & $18(25.4)$ & \multirow{5}{*}{0.871} \\
\hline & 1.5 & $30(75)$ & $10(25)$ & \\
\hline & 2 & $48(76.2)$ & $15(23.8)$ & \\
\hline & 3 & $25(78.1)$ & $7(21.9)$ & \\
\hline & 5 & $30(68.2)$ & $14(31.8)$ & \\
\hline \multirow{2}{*}{ Living with both parents } & Yes & $184(74.5)$ & $63(25.5)$ & \multirow{2}{*}{0.590} \\
\hline & No & $2(66.7)$ & $1(33.3)$ & \\
\hline \multirow{2}{*}{ Living with extended family } & Yes & $46(79.3)$ & $12(20.7)$ & \multirow{2}{*}{0.212} \\
\hline & No & $140(72.9)$ & $52(27.1)$ & \\
\hline \multirow{2}{*}{ Nanny } & Yes & $37(75.5)$ & $12(24.5)$ & \multirow{2}{*}{0.501} \\
\hline & No & 149 (74.1) & $52(25.9)$ & \\
\hline \multirow{2}{*}{ Siblings } & Yes & $143(76.1)$ & $45(23.9)$ & \multirow{2}{*}{0.188} \\
\hline & No & $43(69.4)$ & $19(30.6)$ & \\
\hline \multirow{4}{*}{ Birth order } & First child & $62(73.8)$ & $22(26.2)$ & \multirow{4}{*}{0.065} \\
\hline & Second & $29(60.4)$ & $19(39.6)$ & \\
\hline & Third & $41(82.0)$ & $9(18.0)$ & \\
\hline & Fourth or more & $53(79.1)$ & $14(20.9$ & \\
\hline \multirow{2}{*}{ Attending nursery } & Yes & $13(81.2)$ & $3(18.8$ & \multirow{2}{*}{0.768} \\
\hline & No & 173 (73.9) & $61(26.1)$ & \\
\hline \multirow{2}{*}{ Breastfeeding } & Yes & $132(79.0)$ & $35(21.0)$ & \multirow{2}{*}{0.014} \\
\hline & No & $54(65.1)$ & $29(34.9)$ & \\
\hline \multirow{3}{*}{ Duration of Breastfeeding } & Less than 6 months & 115 (71.9) & $45(28.1)$ & \multirow{3}{*}{0.458} \\
\hline & 6 to less than 12 months & $31(77.5)$ & $9(22.5)$ & \\
\hline & 12 to 24 months & $40(80.0)$ & $10(20.0)$ & \\
\hline \multirow{4}{*}{ Screen time } & No screen time & $33(70.2)$ & $14(29.8)$ & \multirow{4}{*}{0.500} \\
\hline & Not more than 1 hour & 60 (73.2) & $22(26.8)$ & \\
\hline & Within 2 hours & $43(82.7)$ & $9(17.3)$ & \\
\hline & More than 2 hours & $50(74.6)$ & $17(25.4)$ & \\
\hline
\end{tabular}

TABLE 5: Association between children's demographic characteristics and language delay

Demographical and environmental factors of parents who could predict higher risk for language delay in children in the one to five-year age groups

Among the variables of age, level of education, occupation of parents, and family income, none were significantly associated with an increase in language delay among children participating in the study. 


\section{Discussion}

Our study aimed to assess parents' ability to detect language delay early, as it is a prevalent issue in Saudi Arabia [10]. A 2020 study found that a delay in communication skills was one of the most prevalent developmental delays in Saudi Arabian preschool children [14]. The very first few years of a child's life are very important for language development. Parents play a major role in stimulating this skill [15]. A study done in 2019 found that inadequate stimulation by parents is one of the main familial causes of language delay [8]. Using gestures while talking to the child, frequent naming of things around the child's environment, and exposing the child to a variety of experiences are all examples of how parents can stimulate receptive language. Expressive language, on the other hand, can be stimulated by encouraging the child to imitate sounds, using greetings, naming things in the environment, and saying whatever they want with the full attention and response of their parents [16].

As for parents' ability to detect a language delay in their children, our results demonstrated higher rates of undetected language delay in children aged one to two years old. This result might be due to the complexity of language assessment in earlier ages, as language assessment encompass word production and non-verbal communication skills such as eye gaze [17]. Also, parents might think their children will outgrow it or feel that a communication problem is not a high priority [18]. However, it is noteworthy to point out the significance of early detection of language delay, as studies show that speech and language delays that go untreated can continue in $40 \%-60 \%$ of the children and can affect them in both their childhood and adulthood [19-20]. As children, they are at an increased risk of having poor school performance, reading skills, socialization, and attention difficulties [1-2]. As adults, a higher rate of unemployment and low income were reported compared to people with no language delay [7].

Among the variables that have been assessed and could predict a higher risk for language delay, language delay was noticed among children who were not breastfed. Data on this topic are mixed, as some studies suggest that children who are not breastfed are more prone to language delay [21-22]. Some studies revealed no association between breastfeeding and language delay [23]. Birth order was not found to be associated with language delay but some studies suggest that first-born children might have better language skills than later-born siblings [24-25].

In our study, no significant association was found between language delay and a specific gender. However, research suggests that males are at a greater risk for delayed language development than females [26]. No significant difference was also found among children not attending nursery school or having no siblings and language delay. Despite that, children who receive minimal language stimulation tend to be delayed in language development [27]. Finally, our data found no association between language delay and screen time. However, some studies suggest that excessive use of screen time may lead to language delays in children [28-30].

\section{Study strength and limitations}

To the best of our knowledge, this is the first study conducted in Saudi Arabia to assess parents' ability to detect language delays in their children. The result of our study may help raise awareness and shed light on the importance of educating parents about normal developmental milestones and when to seek medical advice. The study involved a self-administered questionnaire in which report bias was possible. Our study was conducted in only three primary health care centers under one tertiary hospital in Riyadh. Therefore, this study does not represent the entire population of Saudi Arabia. Due to the COVID-19 outbreak, we experienced difficulties with data collection. There was a decrease in the number of parents bringing their children to well-baby clinics. Furthermore, some parents refused to participate, as they were afraid to stay in the clinic longer or touch papers or pens.

\section{Conclusions}

The result of this study demonstrated a lack of parents' ability to detect language delays in their children, which may lead to a delay in seeking medical advice and early intervention. Parents' awareness and education regarding the early symptoms of language delay and when to seek medical help is crucial for early detection, intervention, and better quality of life for the children's future. In addition, further research is needed to shed light on this issue and explore more factors related to late diagnosis and management of language delay.

\section{Additional Information Disclosures}

Human subjects: Consent was obtained or waived by all participants in this study. King Abdullah International Medical Research Center, Riyadh, KSA issued approval IRBC/0253/20. Ethical approval was granted by the ethical review board of King Abdullah International Medical Research Center, Riyadh, KSA, Reference \#: IRBC/0253/20. Participant consent was obtained through a consent form. The collected data was stored in a secure place where only the principal investigator and the co-investigators had access. The data did not contain any identifying information. The names of the participants were coded and stored in a 
computer with password protection. Animal subjects: All authors have confirmed that this study did not involve animal subjects or tissue. Conflicts of interest: In compliance with the ICMJE uniform disclosure form, all authors declare the following: Payment/services info: All authors have declared that no financial support was received from any organization for the submitted work. Financial relationships: All authors have declared that they have no financial relationships at present or within the previous three years with any organizations that might have an interest in the submitted work. Other relationships: All authors have declared that there are no other relationships or activities that could appear to have influenced the submitted work.

\section{Acknowledgements}

We would like to extend our thanks to the study participants who volunteered to participate. We would like to express our gratitude and appreciation to Dr. Emad Abdulmajeed for helping in data analysis and to all those who contributed to the validation of the questionnaire. We are also grateful to King Abdullah International Medical Research Center for the permission to conduct the study.

\section{References}

1. McLaughlin MR: Speech and language delay in children. Am Fam Physician. 2011, 83:1183-8.

2. Carter J, Musher K: Etiology of speech and language disorders in children . UpToDate. Post TW (ed): UpToDate, Waltham, MA; 2019.

3. Speech development in children. Accessed: 3/12 . (2019). Accessed: 3/12/2019: https://www.pregnancybirthbaby.org.au/speech-development-in-children .

4. Lipkin PH, Macias MM: Promoting optimal development: identifying infants and young children with developmental disorders through developmental surveillance and screening. Pediatrics. 2020, 145:e20193449. 10.1542/peds.2019-3449

5. Assessing early sociocognitive and language skills in young Saudi children . (2015). https://openaccess.city.ac.uk/id/eprint/13675/.

6. Law J, Boyle J, Harris F, Harkness A, Nye C: Prevalence and natural history of primary speech and language delay: findings from a systematic review of the literature. Int J Lang Commun Disord. 2000, 35:165-88. 10.1080/136828200247133

7. Berkman ND, Wallace I, Watson L, Coyne-Beasley T, Cullen K, Wood C, Lohr KN: Screening for Speech and Language Delays and Disorders in Children Age 5 Years or Younger: A Systematic Review for the U.S. Preventive Services Task Force [Internet]. Agency for Healthcare Research and Quality (US), Rockville MD; 2015.

8. Sunderajan T, Kanhere SV: Speech and language delay in children: prevalence and risk factors . J Family Med Prim Care. 2019, 8:1642-6. 10.4103/jfmpc.jfmpc_162_19

9. Saeed H, Abdulaziz B, AL-Daboon S: Prevalence and risk factors of primary speech and language delay in children less than seven years of age. J Community Med Health Educ. 2018, 8:608. 10.4172/21610711.1000608

10. Fadhli K, Al-Bunaian N: Prevalence and social influences of delayed language development in preschool-age Saudi children. Language Disorders. 2017, 6:6-391.

11. How to tell if your child is a late talker - and what to do about it . (2012). Accessed: 23/12/2021: http://www.hanen.org/Helpful-Info/Articles/How-to-Tell-if-Your-Child-is-a-Late-Talker-\%E2\%80\%93and-W.aspx.

12. Roberts MY, Kaiser AP: Early intervention for toddlers with language delays: a randomized controlled trial . Pediatrics. 2015, 135:686-93. 10.1542/peds.2014-2134

13. Wallace IF, Berkman ND, Watson LR, Coyne-Beasley T, Wood CT, Cullen K, Lohr KN: Screening for speech and language delay in children 5 years old and younger: a systematic review. Pediatrics. 2015, 136:e448-62. 10.1542/peds.2014-3889

14. Shatla MM, Goweda RA: Prevalence and factors associated with developmental delays among preschool children in Saudi Arabia. J High Inst Public Health. 2020, 50:10-7. 10.21608/jhiph.2020.79318

15. Safwat RF, Sheikhany AR: Effect of parent interaction on language development in children . Egyptian Journal of Otolaryngology. 2014, 30:255. 10.4103/1012-5574.138488

16. Language stimulation: guidelines for parents and caregivers. (2019). Accessed: 25/12/2019: https://www.google.com/search?q=www.cincinnatichildrens.org\%2F\%2Fmedia\%2Fcincinnati\%2520childrens\%2Fhome\%2Fservice\%2....

17. Crais ER: Testing and beyond: strategies and tools for evaluating and assessing infants and toddlers . Lang Speech Hear Serv Sch. 2011, 42:341-64. 10.1044/0161-1461(2010/09-0061)

18. How to handle reluctant parents. (2017). https://leader.pubs.asha.org/do/10.1044/helping-parents-acceptspeech-language-treatment/full/.

19. Law J, Rush R, Schoon I, Parsons S: Modeling developmental language difficulties from school entry into adulthood: Literacy, mental health, and employment outcomes. J Speech Lang Hear Res. 2009, 52:1401-16. 10.1044/1092-4388(2009/08-0142)

20. Morgan A, Ttofari Eecen K, Pezic A, et al.: Who to refer for speech therapy at 4 years of age versus who to “watch and wait"?. J Pediatr. 2017, 185:200-204.e1. 10.1016/j.jpeds.2017.02.059

21. Kim KM, Choi JW: Associations between breastfeeding and cognitive function in children from early childhood to school age: a prospective birth cohort study. Int Breastfeed J. 2020, 15:83. 10.1186/s13006-02000326-4

22. Dee DL, Li R, Lee LC, Grummer-Strawn LM: Associations between breastfeeding practices and young children's language and motor skill development. Pediatrics. 2007, 119 Suppl 1:S92-8. 10.1542/peds.2006$2089 \mathrm{~N}$

23. Thorpe K, Rutter M, Greenwood R: Twins as a natural experiment to study the causes of mild language 


\section{Cureus}

delay: II: family interaction risk factors. J Child Psychol Psychiatry. 2003, 44:342-55. 10.1111/14697610.00126

24. Berglund E, Eriksson M, Westerlund M: Communicative skills in relation to gender, birth order, childcare and socioeconomic status in 18-month-old children. Scand J Psychol. 2005, 46:485-91. 10.1111/j.14679450.2005.00480.x

25. Bridges K, Hoff E: Older sibling influences on the language environment and language development of toddlers in bilingual homes. Appl Psycholinguist. 2014, 35:225-41. 10.1017/S0142716412000379

26. Zambrana IM, Pons F, Eadie P, Ystrom E: Trajectories of language delay from age 3 to 5: persistence, recovery and late onset. Int J Lang Commun Disord. 2014, 49:304-16. 10.1111/1460-6984.12073

27. Knight-McKenna M, Hollingsworth HL, Esposito J: Strong beginnings for babies: families' language stimulation of infants from low-income backgrounds. J Child Poverty. 2020, 26:105-24. 10.1080/10796126.2020.1764175

28. Chonchaiya W, Pruksananonda C: Television viewing associates with delayed language development . Acta Paediatr. 2008, 97:977-82. 10.1111/j.1651-2227.2008.00831.x

29. Linebarger DL, Walker D: Infants' and toddlers' television viewing and language outcomes. Am Behav Sci. 2005, 48:624-45. 10.1177/0002764204271505

30. Domingues-Montanari S: Clinical and psychological effects of excessive screen time on children . J Paediatr Child Health. 2017, 53:333-8. 10.1111/jpc.13462 